\title{
Terrain Modeling and Analysis Using Earth Observation System Based Data: A Case Study of Anambra State, Nigeria
}

\author{
E. Ahuchaogu Udo', O. C. Ojinnaka², A. C. Chukwuocha', U. Duru Uchenna ${ }^{1}$ \\ ${ }^{1}$ Department of Surveying and Geo-Informatics, Federal University of Technology Owerri, Owerri, Imo State, Nigeria \\ ${ }^{2}$ Department of Geo-Informatics, and Surveying, University of Nigeria, Enugu Campus, Nsukka, Enugu, Nigeria \\ Email: *udoemmy@yahoo.co.uk
}

How to cite this paper: Udo, E.A., Ojinnaka, O.C., Chukwuocha, A.C. and Uchenna, U.D. (2021) Terrain Modeling and Analysis Using Earth Observation System Based Data: A Case Study of Anambra State, Nigeria. Open Access Library Journal, 8: e7284.

https://doi.org/10.4236/oalib.1107284

Received: March 4, 2021

Accepted: April 27, 2021

Published: April 30, 2021

Copyright $\odot 2021$ by author(s) and Open Access Library Inc.

This work is licensed under the Creative Commons Attribution International License (CC BY 4.0).

http://creativecommons.org/licenses/by/4.0/

\begin{abstract}
We met terrain as the core of our existence therefore good understanding of the topography and other environmental settings improves safety. Mapping and visualization of terrain variable are the bedrock for understanding, protection, management and meaningful development of the physical environment. Integration of remote sensing (RS) and geographic information system (GIS) techniques has proved to be force for sustainable development. Therefore, the aim of this study is to demonstrate how RS and GIS can be used to map and analyze topographical settings in Anambra state as a tool to solve flood hazard related problems. Landsat imagery of $30 \mathrm{~m}$ resolution and SRTM of resolution 30 arc seconds were entered into various GIS software for manipulation and extraction of the topographic features. These datasets were digitally processed to vital topographic features consisting of drainage networks, watershed, flow vectors, contours, Aspect, slopes, 3-D model, Profiles, land use/land cover map, population density map and road map of the study area. These digital derivatives are essential for good understanding of the regions topographical settings for further planning and policy making.
\end{abstract}

\section{Subject Areas \\ Geophysics}

\section{Keywords}

Remote Sensing, GIS, Terrain, Mapping, SRTM

\section{Introduction}

We met terrain as the core of our existence therefore mapping and analysis of 
topographical setting are fundamental for good understanding and management of the physical environment and good knowledge of the environmental settings at a particular time improves safety. Anambra state is annually affected by flood due to its location along the river Niger basin. For example it was one of the worst affected states during 2012 flood episode in Nigeria. Absence of reliable topographic map was among the factors responsible for difficulty in provision of control measure as many areas considered as safe for relief camp were later affected by flood. Notwithstanding the United Nation's specification of 10 and 15 years map revision in remote areas and areas of high human activities respectively, Topographic maps in Nigeria have not been revised for many year ago. Consequently, there is lack of up-to-date topographic maps in many states within the country including Anambra state. For example, Ufuah (2003) [1] reported that the Nigeria 1:50,000 topographic maps adopted as the nation's basic map in 1962, are now old and outdated and no revision of the series has taken place at all. Therefore, it is apparent that such data is no longer faithful for spatial planning. The situation has been of great concern to many planners and scholars in the country. Topographic mapping using current data and modern computer facilities is imperative for sustainable development.

In contemporary times, the use of remote sensing and geographic information systems (GIS) techniques has become the state-of-the-art in map making. GIS is the state of art technology beginning with automated modeling of landscape captured by cameras, digitizers, and scanners (Ajami et al. 2016) [2]. Calogero Schillaci (2015) [3] argued that geographic Information Systems (GIS) allowed the detailed analysis of land surface, whereas the development in Remote Sensing (RS) offered increasingly detailed Digital Elevation Models (DEMs) and multispectral imagery. Remote sensing datasets in combination with GIS have increased the confidence ascribed to outputs in the field of terrain and other environmental analyses. (Sandeep et al. 2013) [4] noted that researchers use GIS and DEM for increasing the quality of landform mapping because it includes 3-D relief features and elevation information. Geospatial researchers have used terrain analysis for visualization of the land surface features. These include drainage pattern, land use, Landforms, etc. The power of visualization cannot be excluded in spatial pattern assessment and this merit is one of the fundamental characters of GIS. For examlpe, Owais et al. (2019) [5] reported that Spatial information pattern assessment and visualization are some of the fundamental characters of GIS.

Initially, environmental analysts encountered difficulty in topographical modeling and analysis especially when it evolved area of wide extent. However, Geospatial technology has made topographical mapping and visualization more accurate, appealing and a large area can be mapped within a far lesser time frame. They enable a large volume of geographic data to be summarized into a map which, without doubt, facilitates fast visual interpretation.

Before the introduction of Digital Elevation Models (DEMs), landforms were only manually identified by means of surveys when available through interpreta- 
tion of aerial photographs (Garbrecht and Martz, 2000) [6]. During world War I, aerial photographs were extensively used to give a view of the enemy's area aiming at a description of the landforms (Pavlopoulos et al., 2009) [7]. During this period, aircraft were equipped with cameras to record enemy movements. Technological advances in the photogrammetry and aerial photography interpretation were made in this period and boosted the topographical analysis. However, Atilola (1986) [8] noted that using the conventional photogrammetric method, it will take not less than 40 years to achieve full coverage of the world at 1:50,000 while the rate of updating cannot be less than every 40 years. It is thus apparent that the mapping needs of the world especially the developing countries, at a scale of 1:5000 and smaller scales, are not being met today by the conventional photogrammetric mapping operations.

Presently, remote sensing and GIS as a means of capturing, and visualization of geographic data is fast replacing the cumbersome conventional technique of data capture and paper topographical map respectively. Digital elevation models (DEMs) are fundamental remote sensing products that support a wide range of applications in environmental modeling. One if their limitations is the presence of offsets where canopy exist (Nwailo et al. 2017) [9]. Yu and Ge, (2010) [10] reported that DEMs have become important sources of topographical data for many scientific and engineering applications such as hydrological and geological studies, infrastructure planning and environmental management. Amy K. Y. Li and Tania Batchvarova (2008) [11] also argued that Digital satellite imagery provides substantial high quality data for mapping, inventorying, monitoring, and its combination with GIS enable visualization of multiple spatial data and presentation of a friendly interface between the map and the user. The sensors onboard the space satellite device is capable of generating extremely high detailed 3-dimensional models of the earth's surface. DEM data has revolutionized the process and quality of topographical maps generation (Ozah \& Kufoniyi, 2008) [12]. When properly manipulated with the right GIS algorithm, remote sensing data can display not only the 3-dimensional (X, Y and Z) attribute and non-attribute data of the landscape but also the river network, watershed, flow direction, slope, aspect, land use/land cover and other numerous topographic and hydrographic features.

\section{Material and Methods}

\subsection{Description of Study Area}

Anambra State is a state in the south eastern part of Nigeria. Gographically, It is located between latitudes $5^{\circ} 40^{\prime} \mathrm{N}$ and $6^{\circ} 50^{\prime} \mathrm{N}$, then longitudes $6^{\circ} 35^{\prime} \mathrm{E}$ and $7^{\circ} 25^{\prime} \mathrm{E}$. It is bordered by delta in the west, Imo and rivers in the south, Enugu in the east and Kogi state in the north. The state has a land mass of approximately 4855 Skm and 2006 population census recorded the state to have a total population of $4,182,032$ with male constituting 2,174,641 and female 2,007,391 fractions of the population. (Emmanuel et al. 2015) [13]. 98\% of the population is Igbos while 
the remaining $2 \%$ of the population are made up of Igala who live in the north western part of the state. Anambra is one of the most populated state in Nigeria with a population density of approximately 900 . Figure 1 is the location map of the study area.

\subsection{Data Collection and Methods}

Data used in this study includes the shuttle radar topographic mission (SRTM) with resolution of $30 \mathrm{~m}$. This was used for generation of topographical models and hydrological features. The topographical models generated include contour lines, 3-D models, Aspect, slopes, and Digital Elevation Model (DEM). The hydrological variables extracted include flow accumulation, flow direction vectors, drainage networks and sub-catchment map. Landsat image with resolution of $30 \mathrm{~m}$ was used for the Land use and land cover (LULC) map of the study area.

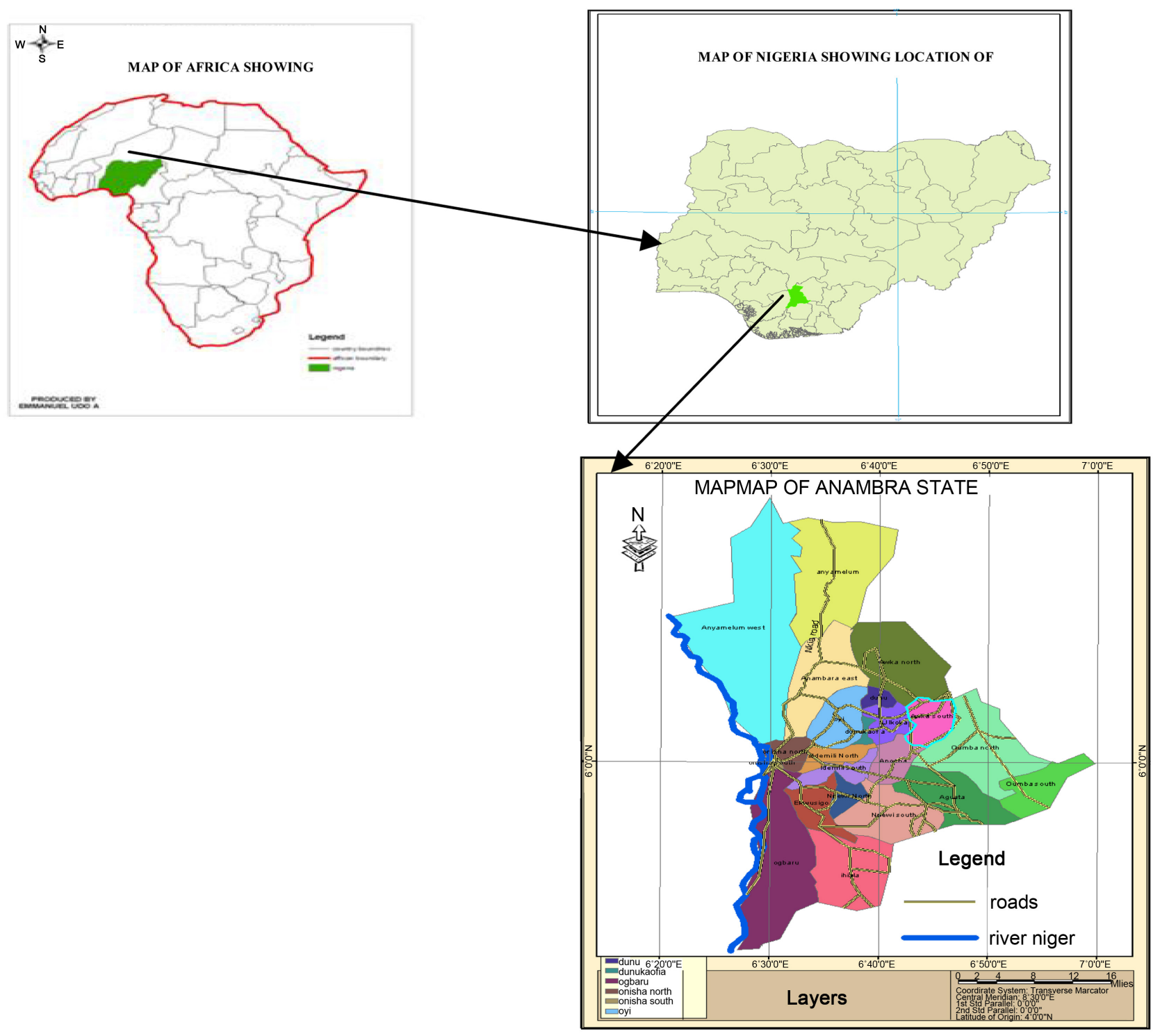

Figure 1. Location map of the study area. 
This was obtained from Global land cover facility (GLCF) while MODIS which was acquired in September 2012 during flood event was downloaded from NASA's web site. The administrative map of the study area from which the boundary and local government area limits shape files was extracted was obtained from Ministry of land of the state. Google earth satellite imagery was obtained from the internet and 2016 population break down of the state was obtained from National population commission within the state. Software used includes ERDARS IMAGINE, Sufer11 and ArcGIS10.3. These were used for image analysis, topographical analysis and feature extraction respectively.

\subsection{Terrain Analysis}

SRTM use in this study consists of four tiles that cover the study area. These elevation raster were added to ArcGIS10.3 window. Progressively, the dataset were mosaicked using mosaic raster extension of data management module of ArcGIS10.3. The merged elevation raster was projected from WGS84 geographic coordinate system (GCS) to WGS 1984 Universal Transverse Mercator zone 32 coordinate system. Area of interested on the elevation feature was sub-mapped using extraction by masking extension of the Spatial Analyst tool in ArcGIS 10.3 software. This was done with the aid of the Anambra state boundary Shape file which has been earlier geo-referenced to UTM zone 32 co-ordinate systems. Subsequently, the masked raster was processed to DEM, slope, Aspect, and Flow accumulation using surface module of spatial analysis extension of ArcGIS 10.3. Using the convert raster to point extension, the masked elevation raster was converted to XYZ, point data and exported to Surfer11 worksheet where a DAT file was created and gridded. The gridded data was subsequently processed to wireframe, 3-D model, flow direction vectors and elevation profiles. These digital derivatives are essential for good understanding of the landscape for planning and decision making.

\subsection{Extraction of Hydrological Features}

The largest river (River Niger) and its major tributary (Omanbala river) within the study area were extracted from the Landsat imagery while other drainage networks were extracted from the elevation raster (SRTM). The hydrology tool and its extensions were used for the extraction of sub-catchment features from the SRTM. The SRTM was subjected to void filling. The void areas are pixels which have heights that are lower than neighboring pixel values when filled the runoff from the DEM will reach its edges. The extraction process identified all the cells of the DEM that ultimately drained to the specified outlet location and the stream network created determined the channels for the watershed. The result of this procedure is the generation of a flow direction grid, which defines the slope (and hence flow direction) of each cell. This grid is fundamental in the mapping of all watersheds, including the flow accumulation grid that was used to define the stream network. These stream networks were digitized and overlaid 
with the river Niger layer extracted from the Landsat imagery.

\subsection{Land Use/Land Cover Analysis}

The image tiles covering the study area were imported to ERDAS Imagine window and mosakiced for a complete coverage. Progressively, the data was projected to UTM zone 32 coordinate system, and area of interest was masked out using the boundary shapefile of the study area. The masked feature was subjected to radiometric and geometric corrections (pre-processing). The preprocessed raster was further subjected to image enhancement to improve the visual distinctions and interpretation. Progressively, un-supervise classification algorithm was use to cluster the pixels in the dataset into categories. The classified data and the Google imagery which has been identified in the same coordinate system were added to ArcGIS 10.3 window for vectorisation. The study area was visited in other to assign the proper LULC categories to the various classes. In the ArcGIS10.3 environment the various classes were digitize and at the same process the road networks were vectorised as layers from the Google earth imagery.

\subsection{Population Density Mapping}

Population density refers to the number of people occupying a square kilometer of land. It can be a valuable tool for emergency responders as it may indicates where a large number of people might be trapped. Besides, high concentration of human activities represents built up areas and the implication of this is that if more runoff is generated than the drainage or river channel can accommodate, as a result of increased impermeable surfaces, flow will overtop the drainage channel or river and flows into buildings or floodplain. In this study, the spatial (administrative elements) and non-spatial (population figures) data were integrated to create a database of population spatial spread of Anambra state.

\section{Result}

In line with the purpose of this study, GIS approach was used to extract vital terrain features from the remote sensed data. As shown in Figures 2-13, the features includes contour lines, DTM, 3-D model wireframe and flow vectors, slope map, Aspect map, profile lines, over lay analysis of drainages and sub-catchment map, land use /land cover map, road map and population density map of the study area. Table 1 revealed spatial coverage of the various land use categories within the study area. These digital derivatives are fundamental for good understanding, policy making and management of the physical environmental.

\subsection{Discussion of Result}

\subsubsection{Contour Lines}

The use of contour line for estimation of landscape characteristics has been the 


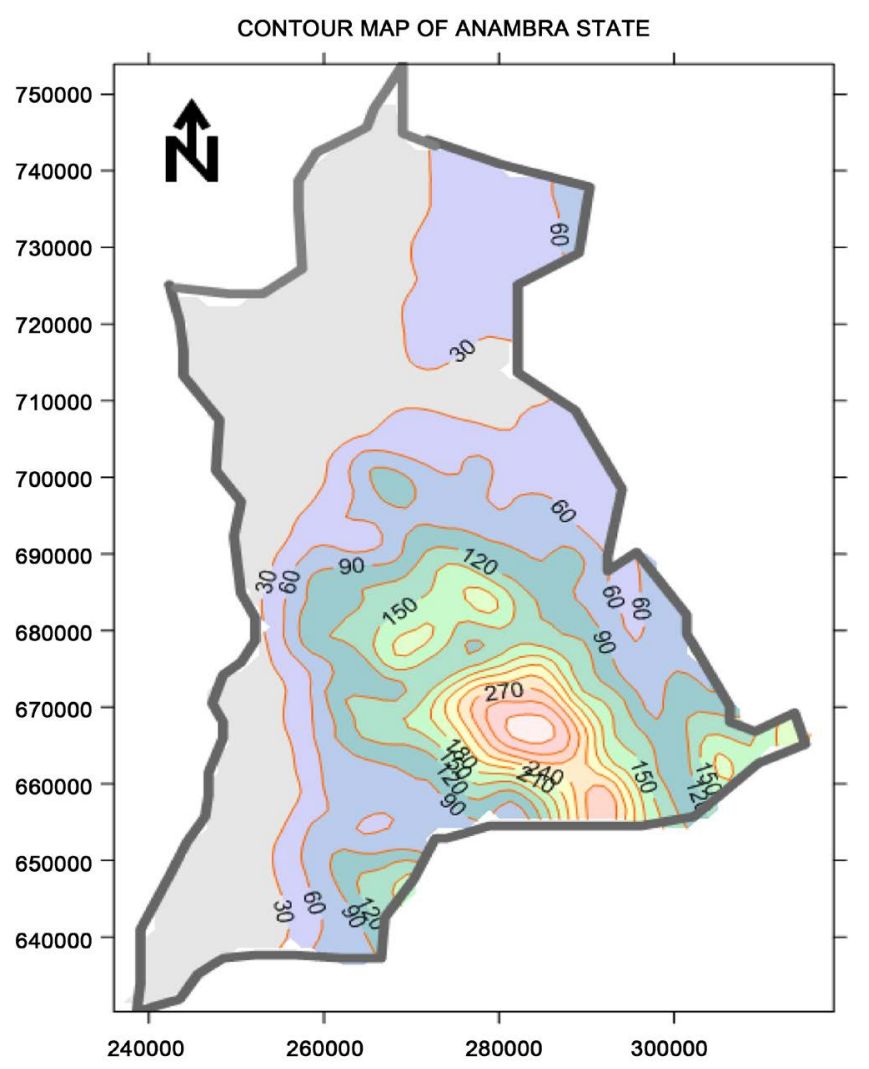

Figure 2. Contour map of the study area.

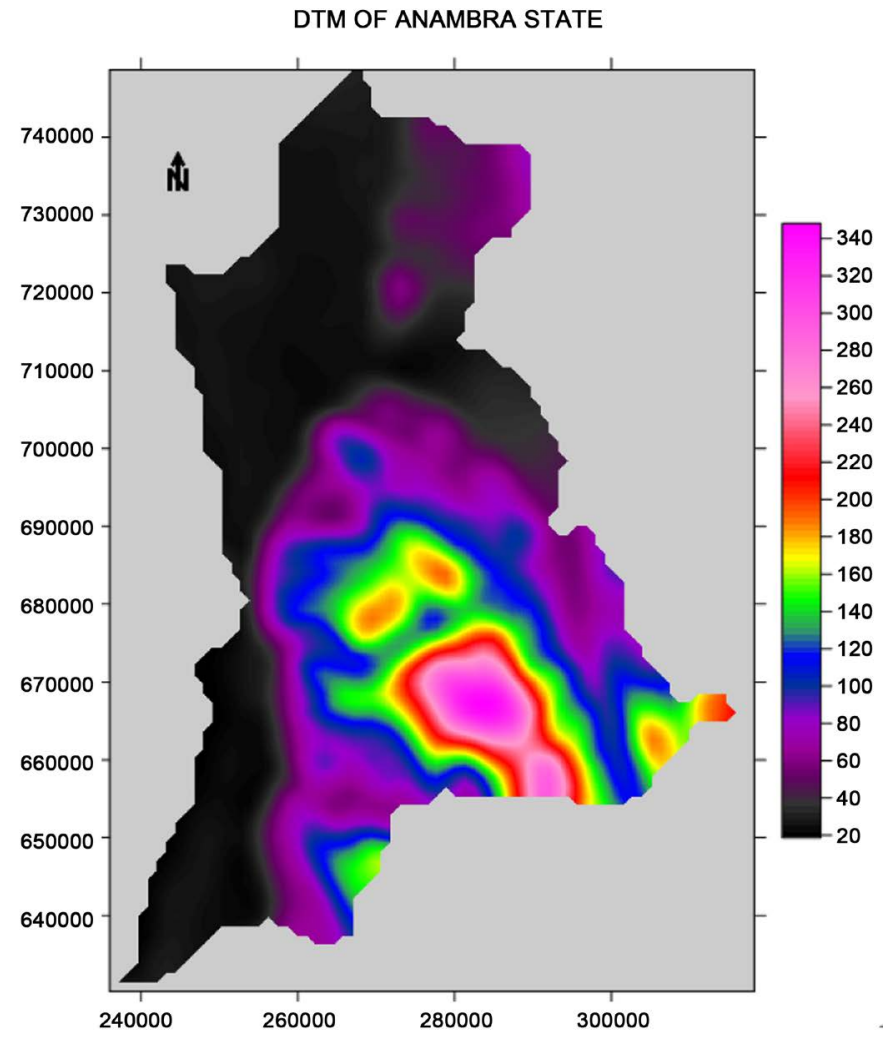

Figure 3. Digital elevation model of the study area. 


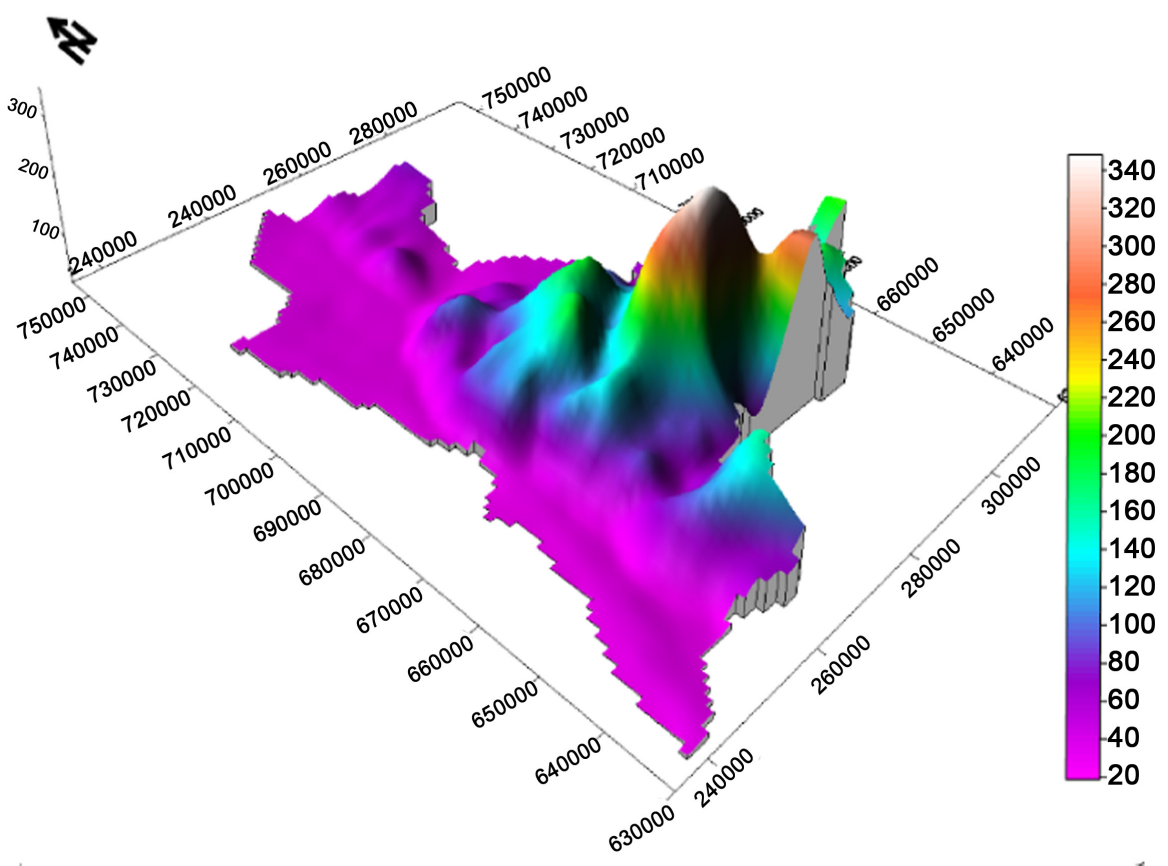

Figure 4. 3-D model of the study area.

\section{OVERLAY ANALYSIS OF FLOW MODELS, AND WIREFRANE OF ANAMBRA SATE}

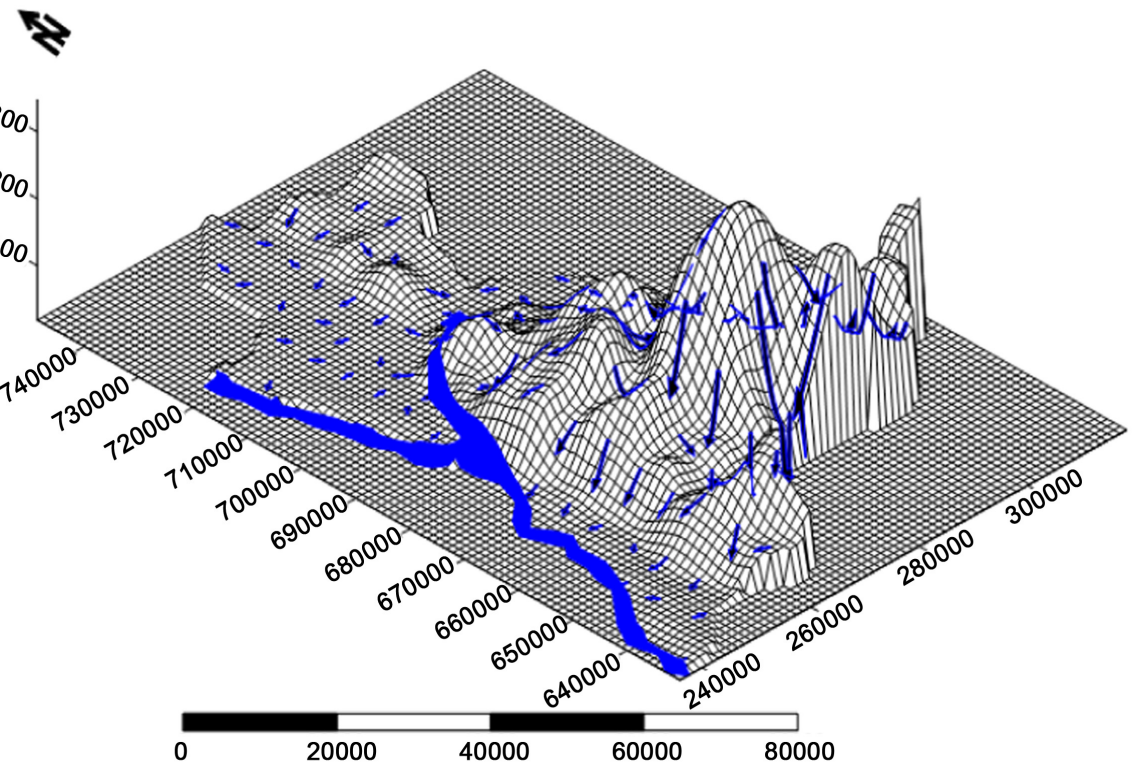

Figure 5. Over lay analysis of river Niger and flow vectors on wire frame of the study area.

most widely accepted method of relief representation before the advent of DEM-based data. It represents elevation and landscape slope gradient simultaneously. The density of the contour lines determines the ruggedness of an area. The results in Figure 2 show hierarchy in topography with reference to height and ruggedness of relief. The Eastern part revealed high spatial cluster in the density of contour lines and generally represents the upland. The contour 


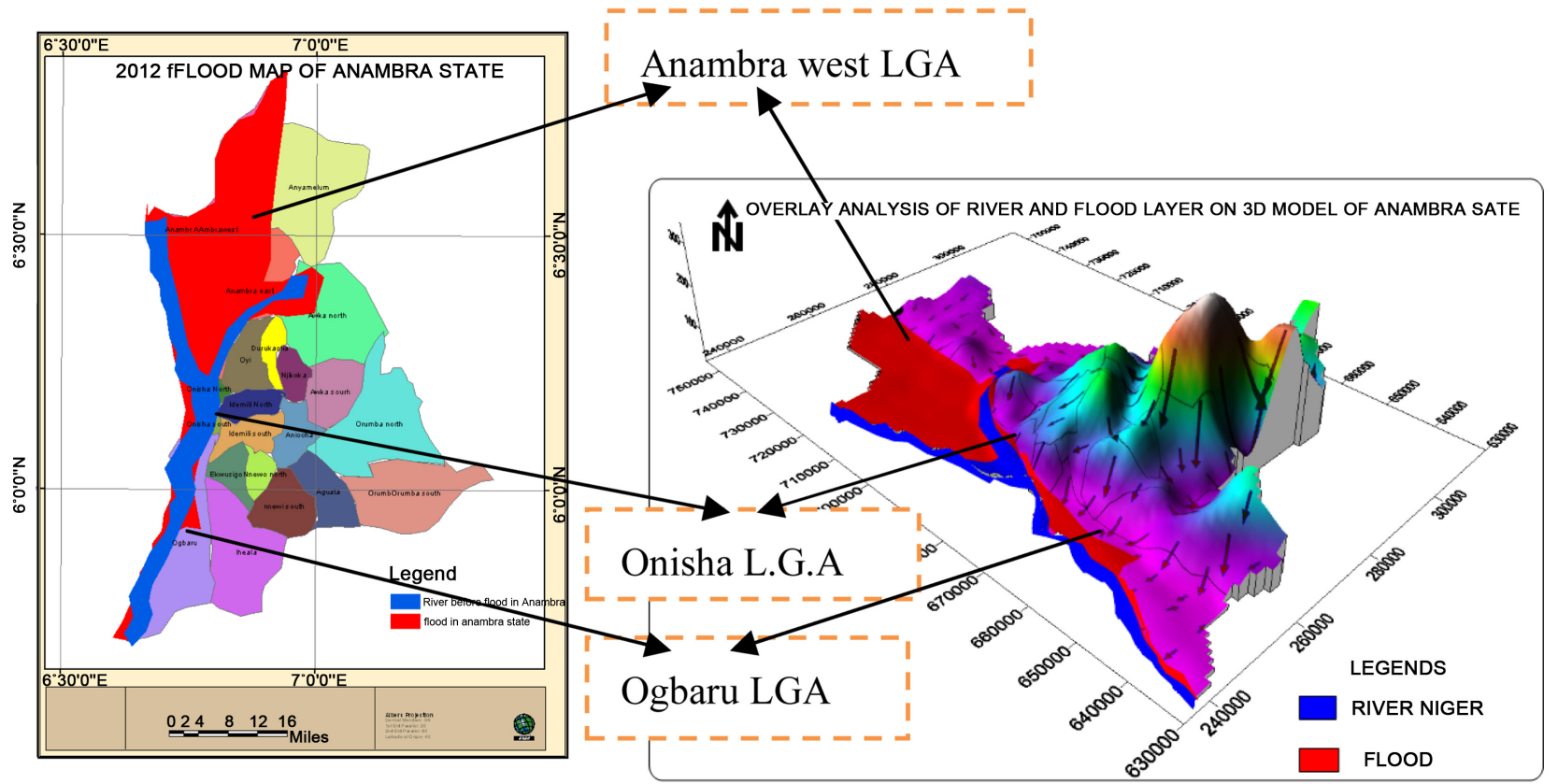

(a)

(b)

Figure 6. (a) flood and river Niger layer on area administrative map of study layers. (b) Flood and river Niger on 3-D Model of the study area.

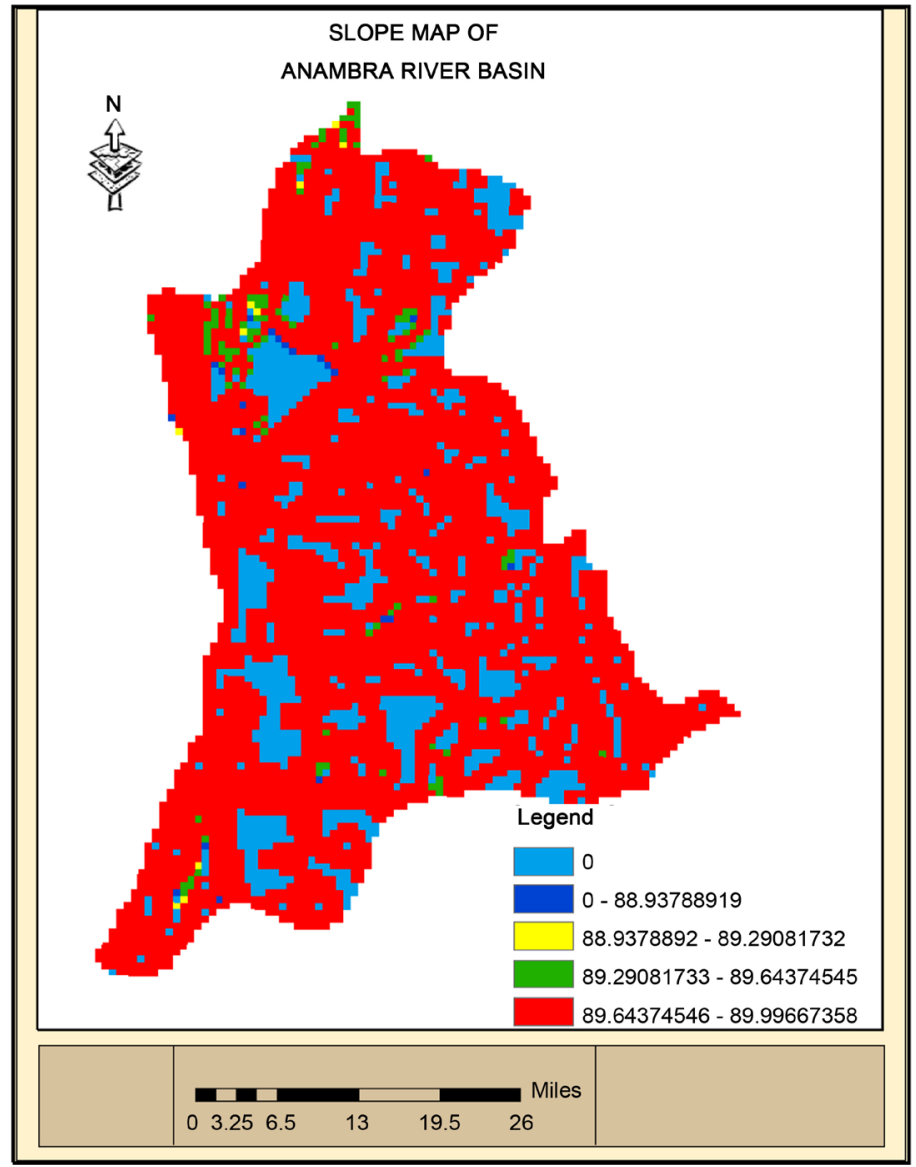

Figure 7. Slope map of the study area. 


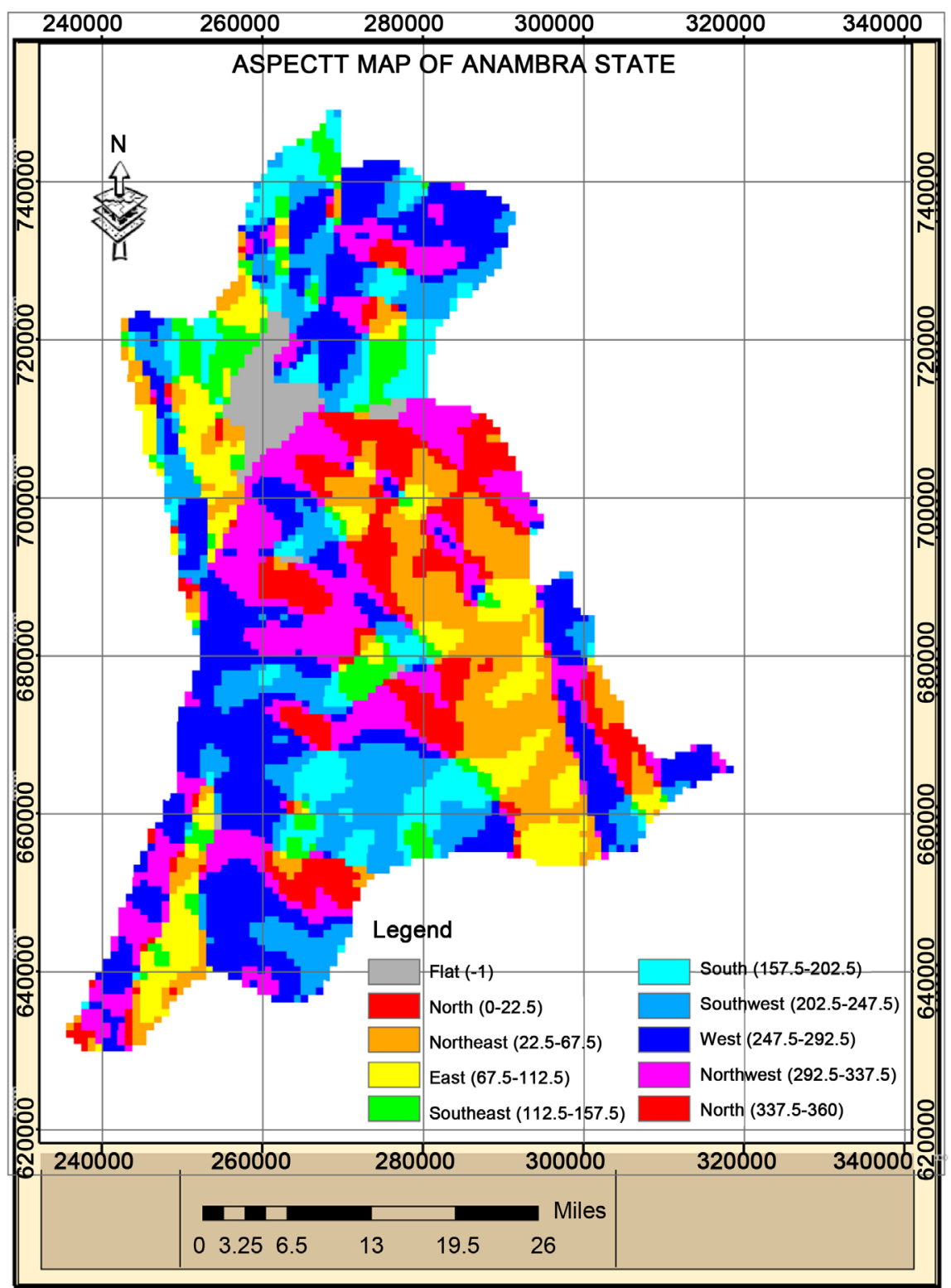

Figure 8. Slope aspect map of the study area.

pattern in the Northern and southern part represents low land areas.

\subsubsection{DEM Analysis}

DEM based approach of topographic analysis uses color variation to portray variation in terrain elevation. Each cell within the DEM when proper manipulated has a unique color which represents a unique symbol representing the height within the cell. These heights within the cells correspond to the positions they occupied in space. This approach of terrain analysis is currently gaining popularity due to its unique characteristics of assigning unique color representing elevation value to every pixel or cell. Figure 3 shows the digital elevation model of the study area. A careful examination shows that the study area is situated within elevation range of $20 \mathrm{~m}$ to $350 \mathrm{~m}$ above mean sea level. 


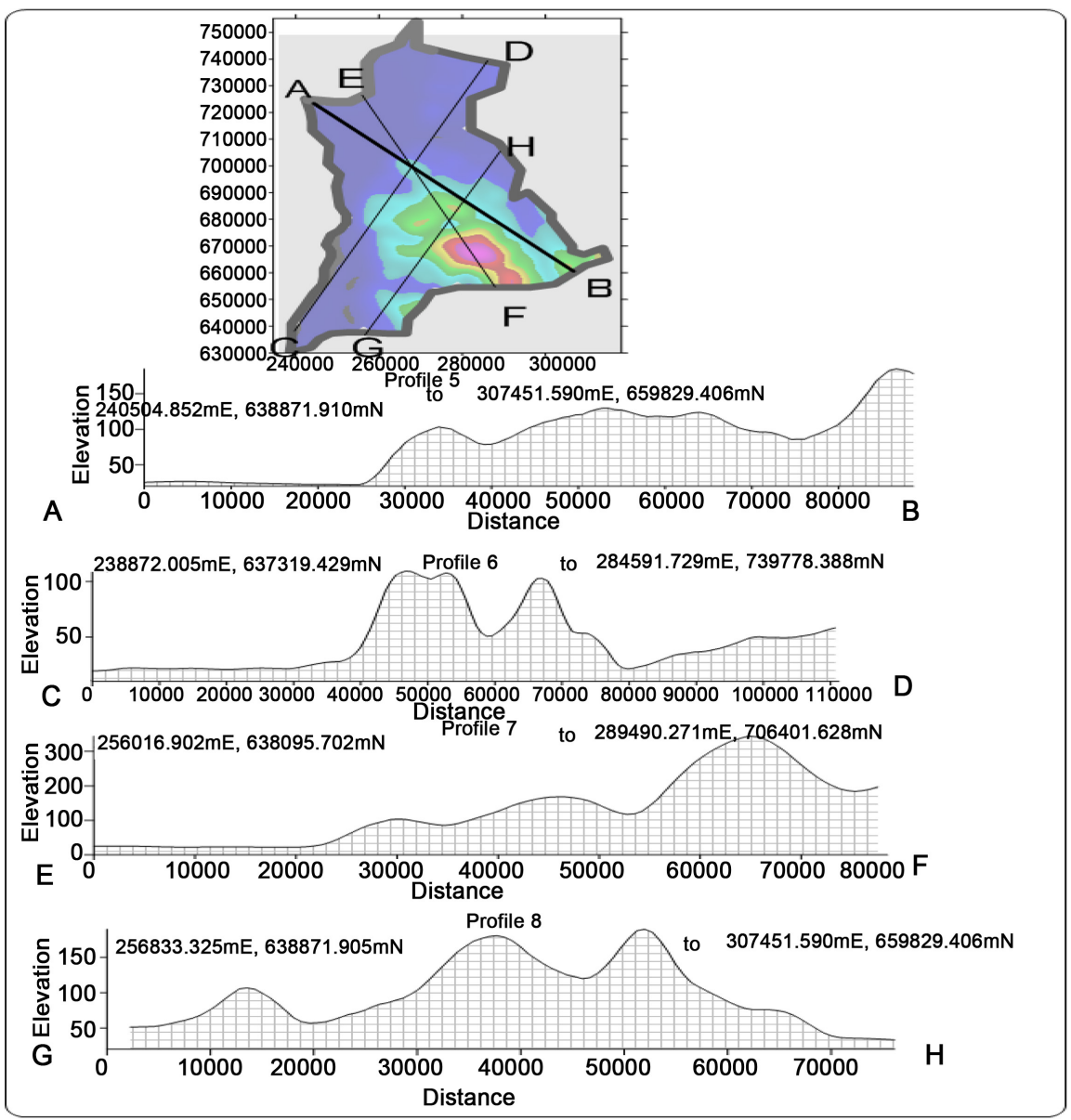

Figure 9. Four elevation profile lines drawn along distinct relief areas. At top is the DEM of the study region showing path profile lines on the surface (A)-(B), (C)-(D), (E)-(F), and $(\mathrm{G})-(\mathrm{H})$.

\subsubsection{3-D Surface Analysis}

Figure 4 and Figure 5 are 3-D model and overlay analysis of the flow vectors and river Niger layer on the wire frame of the study area. This approach of terrain analysis portrays the stereoscopic view of the landscape which is a more realistic view of the real world topography. It enables visual distinction between elevations of different areas to be easily made thereby providing a quick understanding of the terrain. The flow models revealed that surface water, flows towards the river Niger and other low lying areas. The length of the flow vectors is a function of slope magnitude and this influences flow speed. Longer vectors portrays steeper slope and this indicate high flow velocity while the shorter ones depicts flat surfaces and sluggish flow movements. These models assist in visual understanding of the slope magnitude between different locations. Figure 6(a) is overlay analysis of river Niger layer (Blue), flood layer (Red) on the administrative map of Anambra state and Figure 6(b) is the overlay analysis of flood layer on 3-D model of the study area. This analysis visibly shows the influence of relief variation on flood spread within the study area. Its reference to the flood map Figure 6(a) revealed that areas close to river Niger and its major tributary 


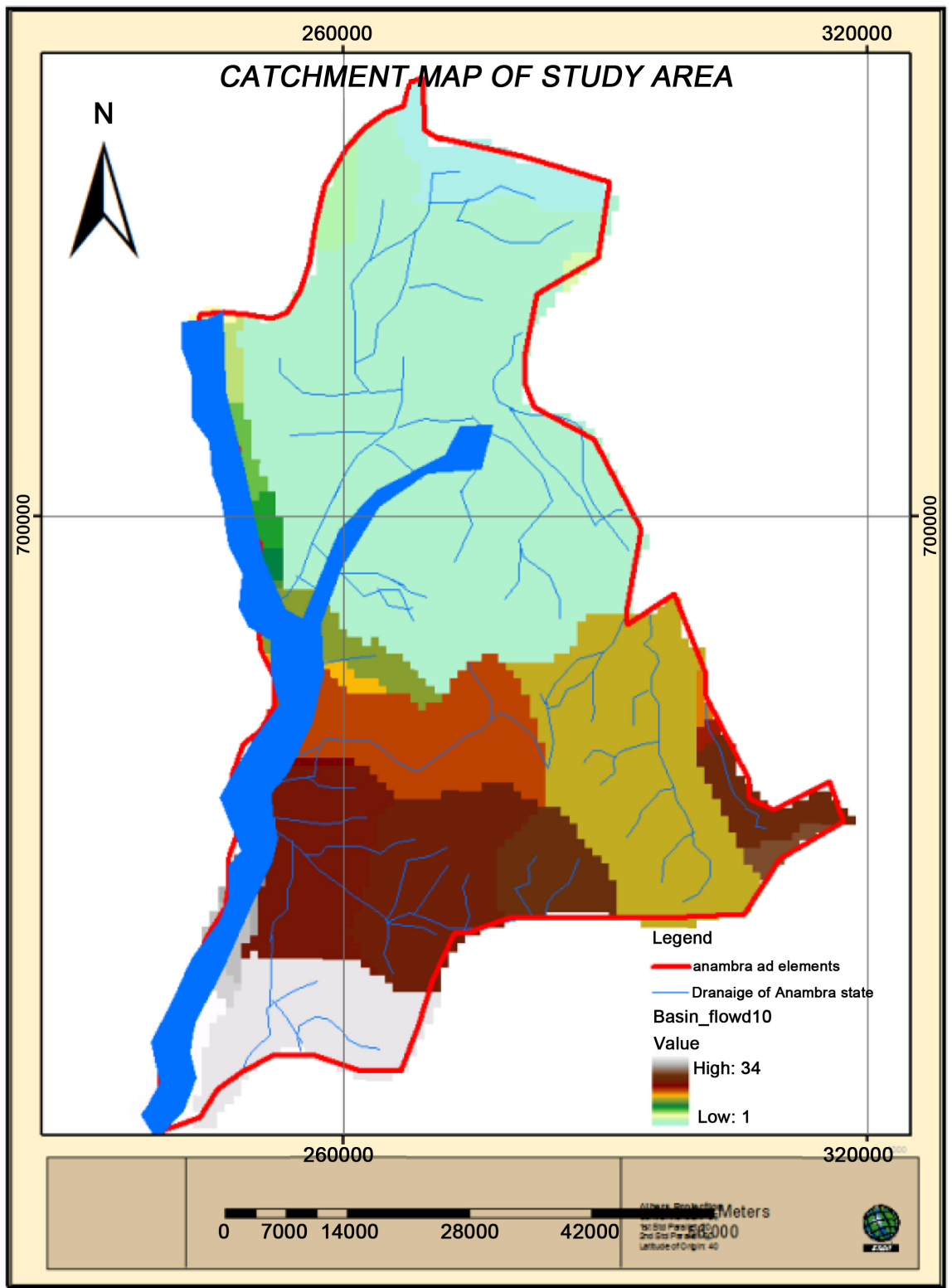

Figure 10. Overlay analysis of drainage on catchment map of the study area.

(Omambala River) is situated in the low relief regions. It further shows that Onisha north, Onisha south, ogbaru, and Anambra west local government areas are under the threat of flood due to their locations within the low lying areas. However, Orumber north, orumba south and Aguata local government areas are located in the upland areas. In terms of elevation, these areas are suitable for relief camp in the event of flood disaster.

\subsubsection{Slope and Aspect}

Figure 7 shows the slope of the river basin, the highest point is above $89 \mathrm{~m}$ while the lowest point shows zero (0) value which indicates total flatness. Slope at a point is calculated as the gradient of the plane formed by the vector connecting the left and right neighbors (run) and the vector connecting the upper and lower 


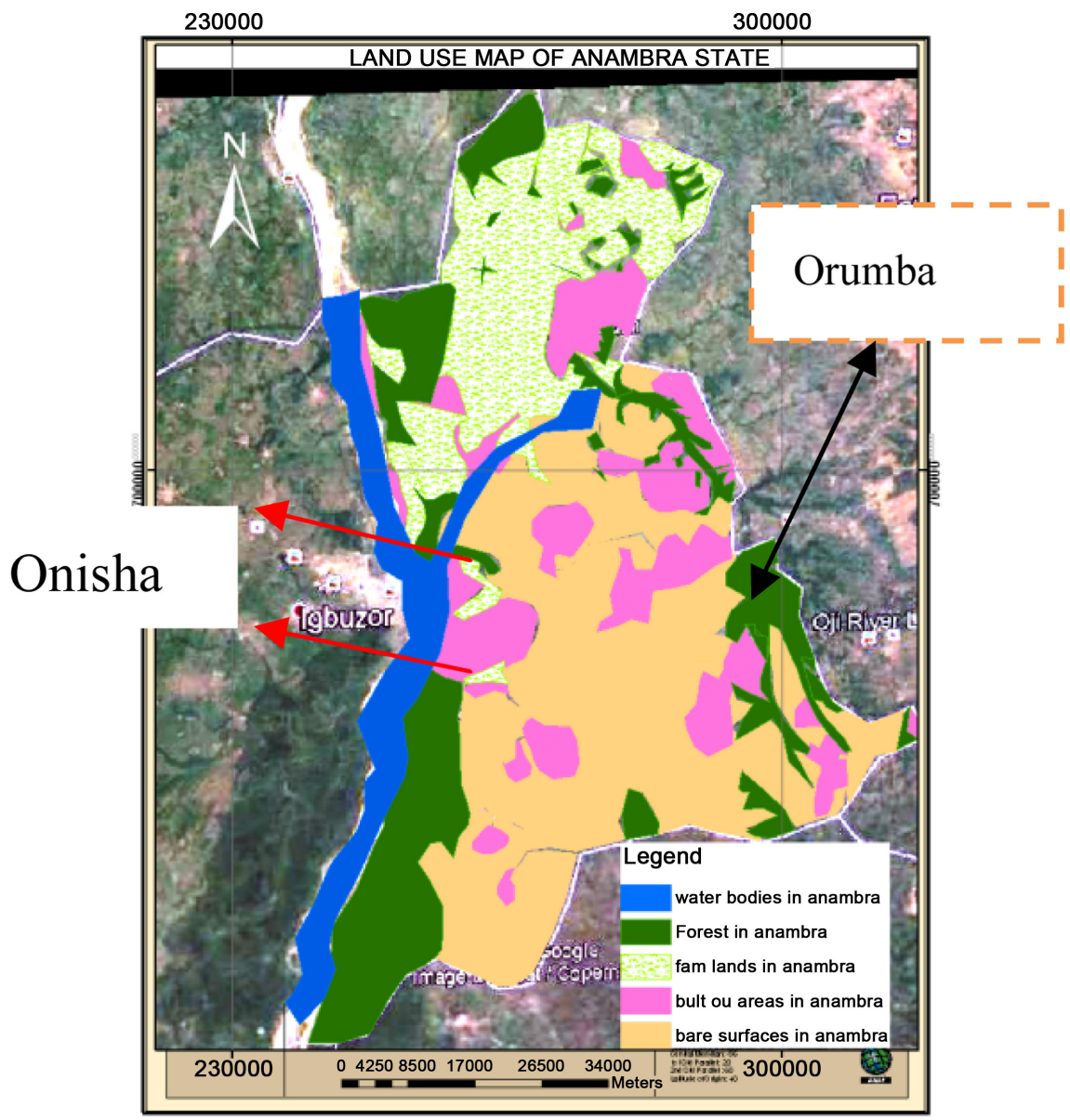

Figure 11. Land use map of the study area.

neighbors' of the pixel (rise) (Ganas et al., 2005) [14]. The magnitude of steepness or the value of surface structure inclination is displayed by the slope of that area. The slope values in an elevation grid of an area range from $0^{0}$ that is flat surface to $90^{\circ}$ that is perfect vertical slope. Aspect (Figure 8) depicts the slope direction and is measured clockwise from $0^{\circ}$ to $360^{\circ}$. It shows the direction of surface water flow. The aspect and slope is invaluable tools for erosion and flood modeling and can also be applied in advance topographical modeling such as estimating the portion of land that will receive high and low solar illumination for agricultural research purposes.

\subsubsection{Longitudinal Profiles}

Profile shape is a prominent method often employ by surveyors, civil engineers, Geomorphologists and Geologists in terrain analysis. This method is particularly helpful when the desired result is to visualize the pattern of mountain ranges, comparing the depth of two or more valleys, visibility analysis between two or more points and showing landscape variation in terms of ruggedness, height, steepness, plane and when chosen the most economic areas for route construction or pipe line laying. Figure 9 shows profiles drawn along distinct and suspicious landforms. Profiles were drawn along (A-B), (C-D), (E-F) and (G-H). 


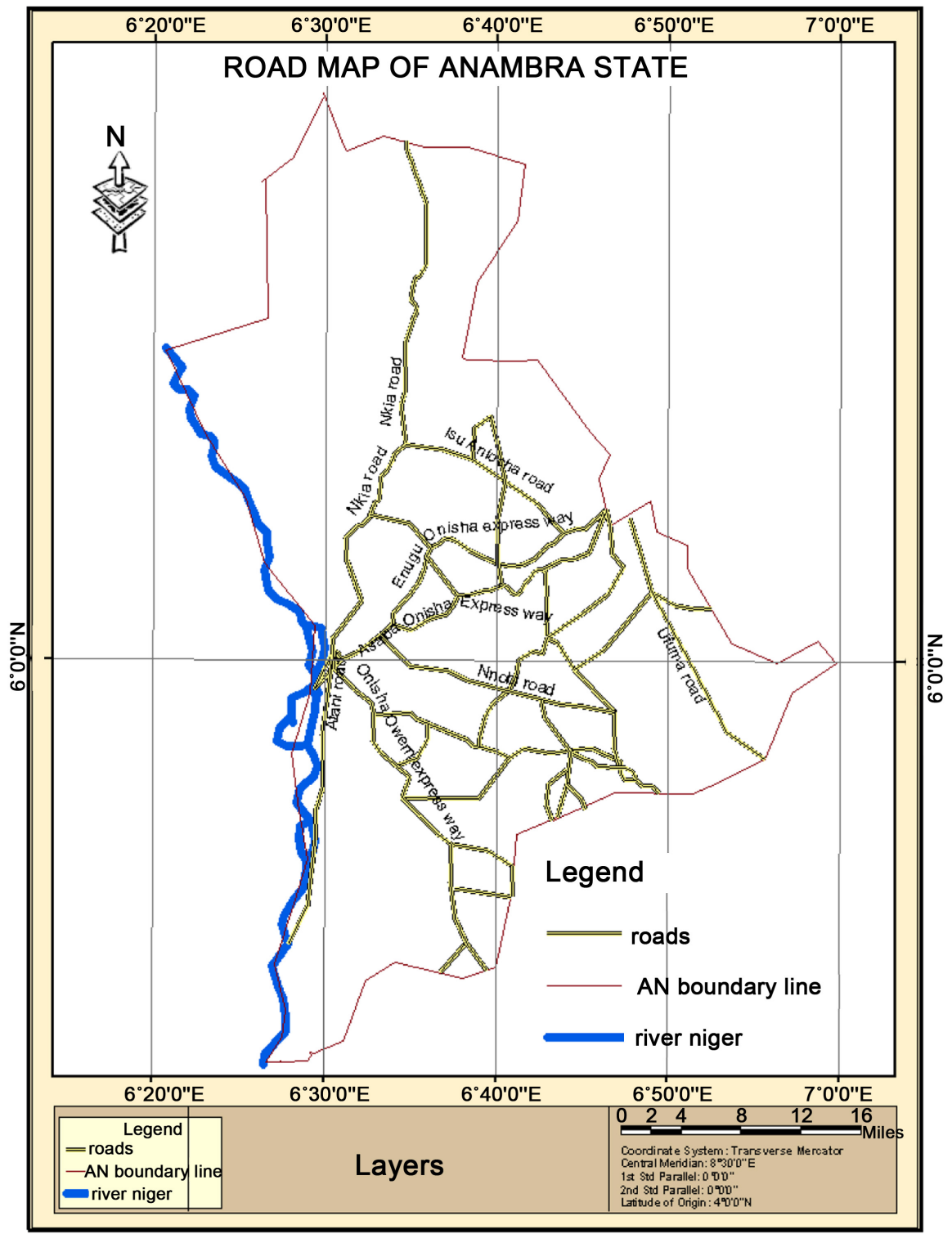

Figure 12. Road map of Anambra state.

These graphics revealed high varied topography between the locations. In addition it revealed flat topography in areas close to river Niger.

\subsubsection{Drainage Analysis}

The result from the drainage investigation (Figure 10) revealed that a good number of the streams are tributaries to river Niger. It revealed categories of $1^{\text {st }}$ to $4^{\text {th }}$ order stream within the network flowing in different directions. Stream order is a notation that shows positions or category of streams in a drainage network or hierarchy. Drainage density is an important hydrological factor in determination of flood potential of a given area. It is expected that a high drainage density indicate large number of impervious surfaces within the basin which results to high flood propensity and low drainage density means low flood potential. Soil permeability and underlying rock type affect the run off in a water 


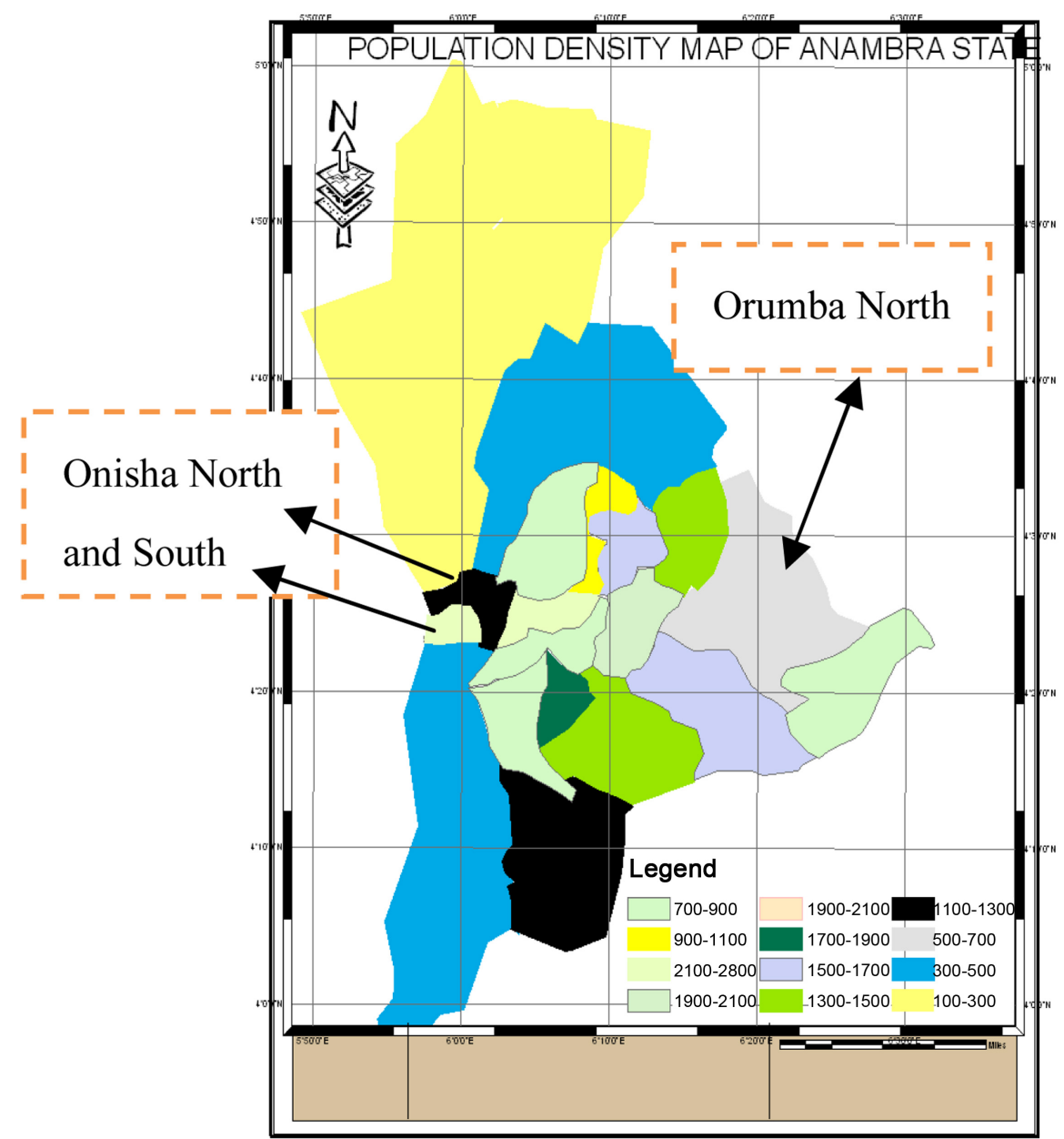

Figure 13. Population density map of Anambra State.

Table 1. Use land cover analysis in Anambra state.

\begin{tabular}{ccc}
\hline $\begin{array}{c}\text { LAND USE LAND } \\
\text { COVER }\end{array}$ & $\begin{array}{c}\text { AREA OF LAND } \\
\text { OCCUPIED } \\
\text { IN km }^{2}\end{array}$ & $\begin{array}{c}\text { PERCENTAGE OF LAND } \\
\text { OCCUPIED BY LAND USE } \\
\text { TYPES }\end{array}$ \\
\hline Built Up Areas & 759.180 & 15.64 \\
Forest Areas & 909.141 & 18.73 \\
Agricultural Lands & 1031.922 & 21.26 \\
Water Bodies & 434.89 & 8.96 \\
Bare Surfaces & 1719.890 & 35.43 \\
\hline
\end{tabular}

shed. Impermeable ground or exposed bedrock will lead to an increase in surface water runoff and therefore to more frequent stream. This study identified a total of 68 streams and 2 rivers within the study area. Further investigation showed that lengths of drainages within the study area when added together measured $752.13 \mathrm{~km}$. This value, having drained in a basin of area 4855 sq kilometers result to a drainage density of $0.155 \mathrm{~km}^{-1}$. Figure 10 is the overlay analysis of the river layers on the watershed map of the study area. This map is invaluable when 
there is need to study the hydrographic terrain of the study area. In most cases, it is utilized for planning agricultural activities and more importantly, it is an indispensable tool for monitoring and tracking down sources of stream pollution. This study also identified a total of 34 sub-catchments within the study area. The largest and smallest watershed occupies area of $816 \mathrm{~km}^{2}$ and $5.0 \mathrm{~km}^{2}$ respectively.

\subsubsection{Land Use/Land Cover Analysis}

Figure 11 revealed a total of five land use categories identified within the study area. These are Built up areas, forest areas, agricultural lands water bodies, and bare surfaces. Further analysis revealed that Built up areas covers $759.180 \mathrm{~km}^{2}$ (15.64\%), forest areas covers $909.141 \mathrm{~km}^{2}$ (18.73\%), agricultural lands covers 1031.922 sqkms $(21.26 \%)$, water bodies covers $434.89 \mathrm{~km}^{2}$. (8.96\%) while bare surfaces covers 1719.890 sqkms (35.43\%). These quantitative attributes are shown in Table 1. A cursory examination revealed that Onisha local government area which is the economic nerve of the state is located close to river Niger and this could be dangerous because any adverse effect from flood will have a negative effect on the economy of the state. However, Orumba north is found to be suitable for relief camp due to its extensive undeveloped land mass (forest) coupled with its moderate relief.

\subsubsection{Road Map of the Study Area}

Many development projects seriously depend on transport network because transportation is the factor determining the speed of growth and development of a place (Vinod et al., 2003) [15]. Whatever the purpose of journey, mode of transport, available route to take, type of vehicle are some of the factors to be considered therefore accurate information on the transport infrastructure is the fundamental requirement for many decision making processes. Information on road network is required to be reliable, updated, relevant, easily accessible and affordable (Fiatornu, 2006) [16]. Transportation is a requirement for every nation, regardless of its industrial capacity, population size or technological development. Moving of goods and people from one place to another is critical to maintaining strong economic and political ties between regions in the same state. Figure 12 is the road network within the study area. A close examination revealed that the networks are rooted from Onisha which is the economic nerve of the state.

\subsubsection{Population Density Map}

Knowing where people are is fundamental for assessment of current and future risk of natural disasters.

It enables the decision makers to better design effective risk reduction and preparedness measures. For example, these maps will help us spot and target support to areas where high concentrations of people overlap with areas at heightened risk of hazard due to climate change. They will also help us rapidly assess affected populations after disasters and better plan for disaster recovery. 
Apart from selection of low population density areas for establishment of relief camp during disaster, the population distribution maps will help us plan for and assess the impact and effect of infrastructure investments on surrounding communities. Figure 13 is the population spatial spread of the study area. selection of suitable locations for internal displaced person's (IDP) camp was a problem in the study area during 2012 flood event in Nigeria. Considering four factors, i.e. moderate high elevation, availability of large expance of undeveloped land, low population density and distance from the river, Orumba North local government was selected as one of the suitable areas for relief camp during similar disaster in future.

\section{Conclusion}

Mapping and analysis of topographical setting are fundamental for good understanding and management of the physical environment. It is needed to enable us familiarize ourselves with the terrain in which development takes place. Besides good knowledge of the environmental settings at a particular time improves safety. In the past environmental analyst relied heavily on analogue methods for modeling and analysis of topography and this approach can no longer satisfy the contemporary planning needs. Based on this, sophisticated method that produces reliable result must be adopted to ensure that the right decision is made during planning. The use of earth observation system (EOS) technology and GIS platform has become an integrated, well developed and reliable approach in topographical analysis. The result of this study revealed the manifold and multi-dimensional capabilities of integrating remote sensing data and GIS in terrain modeling and analysis. The robust methodology developed in the study being evidence by the effectiveness of the results. This can be seen in the series of thematic maps generated, which constitute a geospatial database for informed decision making. With this technique it was possible to map and analyze the landscape and other terrain characteristics and identify a suitable location for IDP camp within the study area. It is therefore recommended that researchers should employ this promising technique for their investigations.

\section{Conflicts of Interest}

The authors declare no conflicts of interest regarding the publication of this paper.

\section{References}

[1] Ufuah, M.E. (2003) Non-Revision of 1:50,000 Topographic Maps and Its Implications for Sustainable Development in Nigeria. Proceeding of the 21 st International Cartographic Association Conference on Cartographic Renaissance, Durban, 10-16 August 2003, 2579-2589.

[2] Ajami, H., Khan, U., Tuteja, N.K. and Sharma, A. (2016) Development of a Computationally Efficient Semi-Distributed Hydrologic Modeling Application for Soil Moisture, Lateral Flow and Runoff Simulation. Environmental Modelling \& Soft- 
ware, 85, 319-331. https://doi.org/10.1016/j.envsoft.2016.09.002

[3] Schillaci, C., Braun, A. and Kropáček, J. (2015) Terrain Analysis and Landform Recognition. In: Geomorphological Techniques, British Society for Geomorphology, London, Chap. 2, 4. 2.

[4] Sandeep, S., Tripathi, S. and Maurya, A.K. (2013) GIS Based Morphometric Characterization of Mini Watershed-Rachhar Nala of Anuppur District Madhya Pradesh. International Journal of Advanced Technology \& Engineering Research, 3, 32-38

[5] Bashir, O., Ali, T., Ram, D., Rather, G.H., Nazir, N., Dar, Q.A.H. and Singh, P. (2019) Application of GIS in Determination and Mapping of Topographic Characteristics of Temperate Himalaya. International Journal of Chemical Studies, 7, 1092-1097.

[6] Garbrecht, J. and Martz, L.W. (2000) Digital Elevation Model Issues in Water Resources Modeling. In: Hydrologic and Hydraulic Modeling Support with Geographic Information Systems, ESRI Press, Redlands, 1-28.

[7] Pavlopoulos, K., Evelpidou, N. and Vassilopoulos, A. (2009) Mapping Geomorphological Environments. Springer, Berlin. https://doi.org/10.1007/978-3-642-01950-0

[8] Atilola (1986) Sensing Practice in Nigeria. International Society for Photogrammetry and Remote Sensing. Proceeding of the Symposium on Photogrammetry and Remote Sensing in Economic Development, Badagry, 22-26 September 1986, 14-21.

[9] Nwilo, P.C., Ayodele, E.G. and Okolie, C.J. (2017) Determination of the Impacts of Landscape Offsets on the 30-Metre SRTM DEM through a Comparative Analysis with Bare-Earth Elevations. Proceeding of FIG Working Week, Surveying the World of Tomorrow from Digitalisation to Augmented Reality, Helsinki, 29 May-2 June 2017, 1-21.

[10] Yu, J.H. and Ge, L. (2010) Digital Elevation Model Generation Using Ascending and Descending Multi-Baseline ALOS/PALSAR Radar Images. Proceeding of FIG Congress, Sydney, 11-16 April 2010, 1-15.

[11] Li, A.K.Y. and Batchvarova, T. (2008) Topographic Mapping and Terrain Modeling from Multi-Sensor Satellite Imagery. Proceeding of the International conference of the Photogrammetry, Remote Sensing and Spatial Information Sciences, 37, Part B1.

[12] Ozah, A.P. and Kufoniyi, O. (2008) Accuracy Assessment of Contour Interpolation from 1:50,000 Topographical Maps and SRTM Data for 1:25,000 Topographical Mapping. Proceeding of the International Conference of the Photogrammetry, and Remote Sensing, Part B7, Beijing.

[13] Emmanuel Udo, A., Ojinnaka, O.C., Baywood, C.N. and Gift, U.A. (2015) Flood Hazard Analysis and Damage Assessment of 2012 Flood in Anambra State Using GIS and Remote Sensing Approach. American Journal of Geographic Information System, 4, 38-51.

[14] Ganas, A., Pavlides, S. and Karastathis, V. (2005) DEM Base Morphometry of Range-Front Escarpments in Attica, Central Greece and Its Relation to Fault Slip Rates. Geomorphology, 65, 301-319. https://doi.org/10.1016/j.geomorph.2004.09.006

[15] Vinod, R.V., Sukumar, B. and Sukumar, A. (2003) Transport Network Analysis of Kasaragod Taluk, Kerala Using GIS. Indian Cartographer, 23, 1-9.

[16] Fiatornu, S.Y. (2006) GIS a Tool for Transportation Infrastructure Planning in Ghana: A Case Study to the Department of Feeder Roads. Proceedings of the 5 th FIG Regional Conference, Accra, 8-11 March 2006, 1-14. 